\title{
Cluster of Differentiation 4 Count and Left Ventricular Diastolic Function in Patients with Hiv - Aids
}

\author{
Farid Hidayat, Dian Pratiwi, Titus Kurnia, Taslim, Ahmad Syukri, Paskalis Indra, Muzakkir Amir, \\ Peter Kabo, Robert Setiadji
}

Cardiac Centre of Wahidin Sudirohusodo General Hospital, Department of Cardiology and Vascular Disease, Medical Faculty of Hasanuddin University, Makassar, Indonesia

\section{Email address:}

faridhidayat26@gmail.com (F. Hidayat), dianpratiwirahim@gmail.com (D. Pratiwi), titus_kurnia@yahoo.com (T. Kurnia) taslimsakka@gmail.com (Taslim), ahmad.syukri.unhas@gmail.com (A. Syukri), paskalis.indra@yahoo.com (P. Indra), dr.muzakkir@gmail.com (M. Amir),drpeterkabo@yahoo.com (P. Kabo), mustika168@gmail.com (R. Setiadji)

\section{To cite this article:}

Farid Hidayat, Dian Pratiwi, Titus Kurnia, Taslim, Ahmad Syukri, Paskalis Indra, Muzakkir Amir, Peter Kabo, Robert Setiadji. Cluster of Differentiation 4 Count and Left Ventricular Diastolic Function in Patients with Hiv - Aids. International Journal of HIV/AIDS Prevention, Education and Behavioural Science. Vol. 4, No. 1, 2018, pp. 5-10. doi: 10.11648/j.ijhpebs.20180401.12

Received: February 23, 2018; Accepted: March 20, 2018; Published: April 12, 2018

\begin{abstract}
Background: People with Acquired Immunodeficiency Syndrome (AIDS) are at risk of developing structural and functional cardiac abnormalities that are unrelated to common cardiac risk factors (e.g. Hypertension, Diabetes Mellitus, Smoking habit). AIDS may be associated with chronic inflammation related to multiple factors related to the Human Immunodeficiency Virus (HIV) infection and its complications. Cardiac abnormality with AIDS may be subclinical and may present long before the onset of clinical heart failure symptoms. Objectives: To anticipate the risk of cardiovascular morbidity in people with AIDS. Methods: The researchers studied 52 people with AIDS in this observational cross-sectional study, which were further categorized into those with cluster of differentiation 4 (CD4) count of less than $200 / \mathrm{mm}^{3}$ and those with CD4 count of more than $200 / \mathrm{mm}^{3}$. Echocardiographic examinations were done to evaluate cardiac structural and functional values. Results: Mean age was 33 years old, predominantly male (71.2\%). The group with a CD4 count of less than 200/mm 3 showed higher Left Ventricular Mass Index (LVMI) values (113.08 vs. 39.99, $\mathrm{p}=0.012)$, a higher risk of developing diastolic dysfunction (OR 9.35, CI 95\%, $\mathrm{p}=0.018$ ) and pericardial effusion (OR 3.83, CI 95\%, $\mathrm{p}=0.048$ ). Conclusion: A CD4 count of less than $200 / \mathrm{mm}^{3}$ is associated with a higher risk of developing cardiac diastolic dysfunction and structural abnormalities.
\end{abstract}

Keywords: HIV, AIDS, Echocardiography, Diastolic Dysfunction

\section{Introduction}

Human Immunodeficiency Virus (HIV) and Acquired Immunodeficiency Syndrome (AIDS) remain a worldwide pandemic, with an estimation of 36.7 million cases worldwide up until 2015; with five million cases found in Asia-Pacific region, including Indonesia.[1]

HIV infection has been well known to be associated with cardiovascular morbidity, represented by a higher risk of cardiovascular disease even in the absence of major conventional cardiovascular risk factors (i.e. dyslipidemia, hypertension, diabetes mellitus, and smoking habit). Various manifestations can be found, including myocarditis, Dilated Cardiomyopathy, pericardial effusion, endocarditis, pulmonary hypertension, and cardiac neoplasm.[2,3] In the era of antiretroviral usage, multiple multicenter studies have shown that diastolic dysfunction, rather than systolic dysfunction is the most common cardiac abnormality found in people with AIDS (43.4\% vs. 8.3\% respectively).[2] Basic pathology of this phenomenon has yet been completely explained, with some theories suggesting chronic infection and inflammation of the left ventricle (LV) as the main cause. [4-7] It is commonly associated with viral replication, nonspecific inflammatory process, antiretroviral use, micronutrient deficiency, and various indirect etiologies. $[8,9]$ In addition, structural abnormality and dysfunction of the LV may be subclinical; it can be found even before the clinical heart failure signs and symptoms appeared. [10] A 
study about these subclinical findings may be useful in order to anticipate the risk of cardiovascular morbidity people with AIDS.

\section{Methods}

\subsection{Study Design}

The study design is an observational cross-sectional study of people with AIDS that were evaluated as they were admitted as outpatients or those who were admitted in the general ward of Wahidin Sudirohusodo General Hospital Makassar, Indonesia. The basic characteristics, clinical and treatment histories, risk factors, and laboratory values were abstracted from medical charts and entered into an electronic database. These data were then reviewed and double-checked for validity by trained staff. Additional data were collected through physical examination and echocardiography measurements. The local hospital ethical committee was approved the study protocol.

\subsection{Laboratory Evaluation}

The basic cluster of differentiation 4 (CD4) cell count was done in the Wahidin Sudirohusodo General Hospital's central laboratory. Other clinical laboratory tests that were performed were basic hematology panel, high density lipoprotein (HDL), low density lipoprotein (LDL), total cholesterol (TC), and triglyceride (Tg), glucose, C-reactive protein (CRP), D dimer, ureum and creatinine; all were done in the same laboratory.

\subsection{Echocardiographic Measurements}

In this study, experienced echocardiographers who were blinded to the study performed the echocardiography examinations. The examination results were recorded digitally and then interpreted by one experienced reader blinded to the study. The Left Ventricular End Systolic and End Diastolic volumes were determined using the biplane modified Simpsons method to obtain the left ventricular ejection fraction. ${ }^{8}$ Other measurements, including left ventricular mass index, Left Atrium and Right Atrium volume, Tricuspid Annular Plane Systolic Excursion (TAPSE), early (E) and late diastolic (A) mitral inflow velocity, deceleration time, and Tissue Doppler Imaging were also obtained.

\subsection{Echocardiographic Outcomes}

Various echocardiographic outcomes were being studied: the LV diastolic function, the LV systolic function, LV systolic function, LV chamber quantification, and the rest of cardiac chamber size. LV diastolic function was represented by the Doppler peak early (E) and late diastolic (A) mitral inflow velocity, E/A ratio, mitral inflow deceleration time, and lateral mitral annular velocity (E') on tissue Doppler. LV diastolic dysfunction was further classified into three categories [11], the first degree of diastolic dysfunction was defined as E/A ratio of less than 0.8 , with deceleration time of more than $200 \mathrm{~ms}$ [12]; the second degree was defined as E/A ratio of $0.8-1.5$ with deceleration time of $160-200 \mathrm{~ms}$ (or with the founding of E/A ratio change during valsalva maneuver equals 0.5) [13], and the third degree was defined as E/A ratio of more than two, with deceleration time of less than 160 of ms. [11, 13] LV systolic function was represented by the Ejection Fraction (EF) which was determined using Simpson biplane method, where the normal category is defined as EF of more than $55 \%$.[6], [14] LV chamber quantification was represented by the LV mass index (LVMI) and Relative Wall thickness (RWT). [14, 15] LVMI was calculated using the standard validated formula recommended by the American Society of Echocardiography (ASE). Values of LV mass were each normalized to the body surface area (BSA). RWT was calculated by the standard validated formula and then used in conjunction with the LVMI to define the LV geometry. Normal LV geometry was defined as LVMI of less than $115 \mathrm{~g} / \mathrm{m}^{2}$ in men (Male) and less than $95 \mathrm{~g} / \mathrm{m}^{2}$ in women with the RWT value of less than 0.42 . [16] Concentric LV remodeling was defined as LVMI of less than $115 \mathrm{~g} / \mathrm{m}^{2}$ (men) and less than $95 \mathrm{~g} / \mathrm{m}^{2}$ (women) with the RWT value of less than 0.42 . Concentric LV Hypertrophy (LVH) was defined as LVMI of more than $115 \mathrm{~g} / \mathrm{m}^{2}$ (men) and more than $95 \mathrm{~g} / \mathrm{m}^{2}$ (women) with the RWT value of more than 0.42 . Eccentric LVH was defined as LVMI of more than $115 \mathrm{~g} / \mathrm{m}^{2}$ (men) and more than $95 \mathrm{~g} / \mathrm{m}^{2}$ (women) with the RWT value of less than 0.42 . [16]

\subsection{Statistical Analysis}

Computed analyzing was performed for all the data analysis. Bivariate spearman correlation was used to determine the correlation between various numerical variables and CD4 count with the diastolic echocardiographic outcomes. Multivariate logistic regression analysis between the CD4 count categories was then performed as a comparison of the echocardiographic diastolic dysfunction outcomes. Statistical testing was conducted at the Confidence Interval (CI) of 95\%. Data were analyzed using SPSS software version 23 (IBM corporation).

\section{Results}

\subsection{Baseline Characteristics}

Among 52 patients, the mean age was 33 years old, $71.2 \%$ were male, and $28.8 \%$ were female. $75 \%$ were underweight with mean BMI of $16.5 \mathrm{~kg} / \mathrm{m}^{2}(12.8-22.4$ $\mathrm{kg} / \mathrm{m}^{2}$ ). Mean heart rate was 96.7 beats/minute. The mean CD4 level was $205.7 / \mathrm{mm}^{3}$ with $25(48.1 \%)$ patients having a CD4 count of less than $200 / \mathrm{mm}^{3}$ and $27(51.9 \%)$ patients having a CD4 count of more than $200 / \mathrm{mm}^{3}$. The mean troponin level was $0.062 \mathrm{ng} / \mathrm{dl}$, with $32.7 \%$ of patients having elevated troponin levels. An elevated CPR was found among $67.3 \%$ of patients (mean values 205.7 $\mathrm{mg} / \mathrm{l})$. The mean leukocyte count was 7057.6/uL. Additional characteristics are shown in Table 1. 
Table 1. Baseline Characteristics of HIV/AIDS Patients Based on the CD4 Count.

\begin{tabular}{lll}
\hline & CD4 $<\mathbf{2 0 0} / \mathbf{m m}^{\mathbf{3}}$ & $\mathbf{C D 4}>\mathbf{2 0 0} / \mathbf{m m}^{\mathbf{3}}$ \\
\cline { 2 - 3 } & $\mathbf{( n = 2 5 )}$ & $\mathbf{( n = 2 7 )}$ \\
\hline Age (years) & $32.6 \pm 5.9$ & $33.9 \pm 6.9$ \\
Male (\%) & 76 & 66.7 \\
Body Mass Index $\left(\mathrm{kg} / \mathrm{m}^{2}\right)$ & $16.1 \pm 2.1$ & $16.8 \pm 2.1$ \\
Heart Rate (bpm) & $100 \pm 12.8$ & $93 \pm 15.7$ \\
Systolic BP $(\mathrm{mmHg})$ & $112 \pm 10$ & $112 \pm 8$ \\
Diastolic BP $(\mathrm{mmHg})$ & $72 \pm 6.4$ & $71 \pm 5.7$ \\
Laboratory Values & & \\
CD4 count $\left.(/ \mathrm{mm})^{3}\right)$ & $66.1 \pm 58.2$ & $335.0 \pm 105.8$ \\
Troponin I (ng/dL) & $0.07 \pm 0.11$ & $0.04 \pm 0.09$ \\
CRP (mg/dL) & $29.7 \pm 40.2$ & $42.1 \pm 53.6$ \\
D-dimer $(\mathrm{ng} / \mathrm{dL})$ & $1.3 \pm 1.5$ & $0.79 \pm 1.4$ \\
WBC(/uL) & $7952 \pm 7265$ & $6229.6 \pm 5429.8$ \\
Hb (g/dL) & $9.1 \pm 2.7$ & $10.2 \pm 2.2$ \\
PLT(/uL) & $252,520 \pm 133635$ & $221,025 \pm 103,097$ \\
Ureum (mg/dL) & $24.6 \pm 9.7$ & $22.7 \pm 9.0$ \\
Creatinine (mg/dL) & $0.7 \pm 0.26$ & $0.70 \pm 0.22$ \\
RBG(mg/dL) & $100.6 \pm 19.9$ & $107.2 \pm 30.6$ \\
Total Cholesterol(mg/dL) & $143.0 \pm 61.8$ & $167.2 \pm 61.8$ \\
HDL Cholesterol (mg/dL) & $24.1 \pm 16.5$ & $28.5 \pm 12.0$ \\
LDL Cholesterol (mg/dL) & $93.5 \pm 58.2$ & $110.0 \pm 48.7$ \\
Triglyceride (mg/dL) & $189.4 \pm 79.2$ & $188.3 \pm 83.5$ \\
\hline
\end{tabular}

CD4, Cluster of differentiation 4; BP, Blood Pressure; CRP, C-Reactive Protein; WBC, White Blood Cell; Hb, Haemoglobin; PLT, Platelet; RBG, Random Blood Glucose; HDL, High Density Lipoprotein; LDL, Low Density Lipoprotein

\subsection{Baseline Echocardiography Findings}

Table 2. Echocardiography Parameters in HIV/AIDS Patients Based On Their CD4 Count.

\begin{tabular}{|c|c|c|c|}
\hline \multirow{2}{*}{$\begin{array}{l}\text { Echocardiography } \\
\text { Parameters }\end{array}$} & \multicolumn{2}{|l|}{ CD4 } & \multirow{2}{*}{$\mathbf{p}$} \\
\hline & $<200 / \mathrm{mm}^{3}$ & $>200 \mathrm{~mm}^{3}$ & \\
\hline $\mathrm{E}(\mathrm{m} / \mathrm{s})$ & 0.67 & 0.71 & 0.418 \\
\hline $\mathrm{A}(\mathrm{m} / \mathrm{s})$ & 0.78 & 0.15 & 0.057 \\
\hline $\mathrm{E} / \mathrm{A}$ ratio & 0.87 & 1.07 & 0.026 \\
\hline Deceleration Time (ms) & 211.6 & 185.2 & 0.015 \\
\hline LVEF (\%) & 61.6 & 64.8 & 0.138 \\
\hline LVIDd (mm) & 44.8 & 42.3 & 0.097 \\
\hline $\operatorname{IVSD}(\mathrm{mm})$ & 9.16 & 8.63 & 0.365 \\
\hline LVPWd (mm) & 10.0 & 9.2 & 0.053 \\
\hline $\operatorname{LVMI}\left(\mathrm{g} / \mathrm{m}^{2}\right)$ & 113.08 & 39.99 & 0.012 \\
\hline RWT & 0.45 & 0.44 & 0.501 \\
\hline LA diameter $(\mathrm{cm})$ & 2.85 & 2.75 & 0.459 \\
\hline TAPSE $(\mathrm{cm})$ & 2.01 & 2.01 & 0.913 \\
\hline Right Atrial Pressure (mmHg) & 4.20 & 3.74 & 0.411 \\
\hline RV Free Wall Thickness (cm) & 0.61 & 0.53 & 0.027 \\
\hline PVAccT (ms) & 97.76 & 110.13 & 0.123 \\
\hline mPAP (mmHg) & 35.01 & 29.44 & 0.123 \\
\hline
\end{tabular}

CD4, Cluster of differentiation 4; E, early diastolic mitral inflow velocity; A, late diastolic mitral inflow velocity; LVEF, Left Ventricular Ejection Fraction; LVIDd, Left Ventricular Internal Diameter End Diastole; IVSD, Interventricular septal end diastole, LVPWd, Left Ventricular Posterior Wall End Diastole; LVMI, Left Ventricular Mass Index; RWT, Relative Wall Thickness; LA, Left Atrium; TAPSE, Tricuspid Annular Plane Systolic Excursion; RV, Right Ventricle; PVAccT, Pulmonary Vein Acceleration Time; mPAP, Mean Pulmonary Artery Pressure
The Ejection Fraction ranges from 41.0 - 74.1\% (Mean $63.2 \%$ ); 5.8\% patients had a depressed Ejection Fraction (of less than $50 \%)$. Thirty four $(65.4 \%)$ of the patients had an abnormal diastolic dysfunction, $31(59.6 \%)$ had a grade one diastolic dysfunction, while $3(5.8 \%)$ had a grade two diastolic dysfunction. Mean E velocity was $0.69 \pm 0.17 \mathrm{~m} / \mathrm{s}$, A velocity was $0.747 \pm 0.16 \mathrm{~m} / \mathrm{s}$, and Deceleration time was $197.8 \pm 39.5 \mathrm{~ms}$. The mean $\mathrm{E} / \mathrm{A}$ ratio was $0.98 \pm 0.32$. The mean LVMI was $100.1 \pm 36.6 \mathrm{gr} / \mathrm{m}^{2}$ with a mean of RWT of $0.44 \pm 0.07$. Among 52 patients, $38.5 \%$ had a concentric remodeling, $32.7 \%$ had a normal LV geometry, $23.1 \%$ had a concentric hypertrophy and only 5.8\% had an eccentric hypertrophy. Most patients $(90.4 \%)$ had a normal regional wall motion and no pericardial effusion (73.1\%). Other echocardiography findings are listed in Table 2. Patients with a CD4 count of less than $200 / \mathrm{mm}^{3}$ had higher LVMI than those with a CD4 count of more than $200 / \mathrm{mm}^{3}$ (113.08 vs. 39.99, $p=0.012$ ).

\subsection{CD4 Count Correlation to the Echocardiographic Findings}

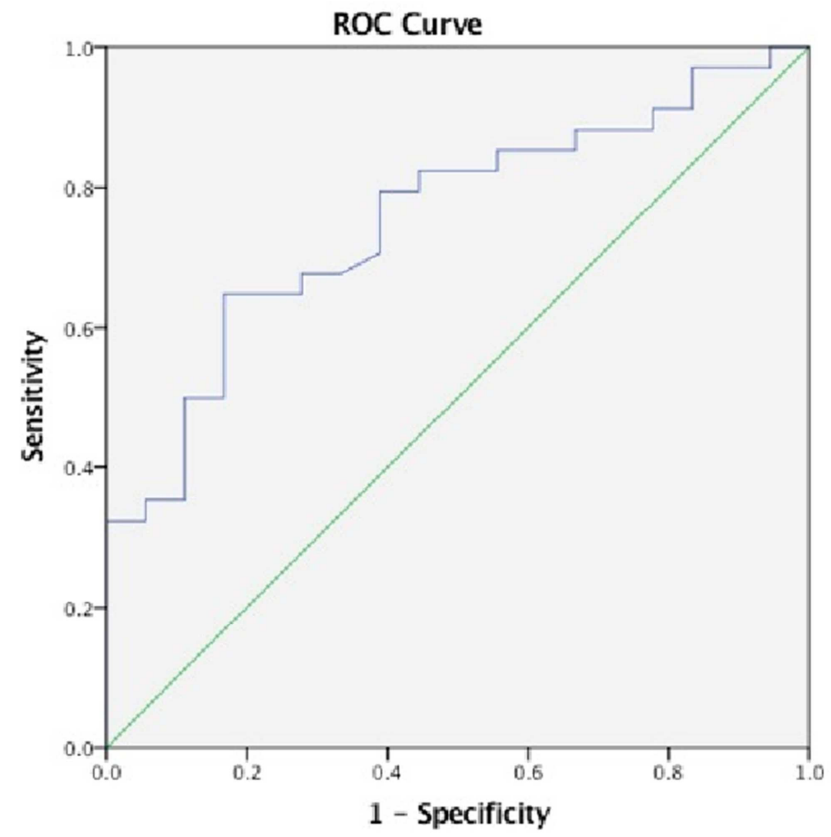

Figure 1. Area Under the Curve for CD4 count $<200 / \mathrm{mm}^{3}$.

There was no significant difference in the E velocity and A velocity between patients with a CD4 count of less than $200 / \mathrm{mm}^{3}$ and those with a CD4 count more than $200 / \mathrm{mm}^{3}$ $(0.679 \pm 0.18$ vs. $0.718 \pm 0.16, p=0.418$ and $0.786 \pm 0.15$ vs. $0.700 \pm 0.15, p=0.057$, respectively). Patients with a CD4 count of less than $200 / \mathrm{mm}^{3}$ had a significant higher deceleration time than those with CD4 count of more than $200 / \mathrm{mm}^{3}(211.6 \pm 29.4$ vs. $185.2 \pm 43.8, p=0.01)$. Bivariate Spearman correlation showed a significant moderate correlation between CD4 count and the diastolic dysfunction grade $(\mathrm{r}=-0.427, p=0.002)$. The lower CD4 count was associated with the higher grade of diastolic dysfunction. We found no significant correlation between CD4 count and 
other functional echocardiographic findings such as LV ejection fraction $(p=0.329)$, regional wall motion $(p=$ $0.480)$, and LVH types $(p=0.535)$. Multivariate regression analysis showed a CD4 count of less than $200 / \mathrm{mm}^{3}$ significantly predicts diastolic dysfunction (Odds Ratio [OR], 9.35, CI 95\%; $p=0.018$ )

\section{Discussion}

Structural and functional cardiovascular abnormalities are not uncommon in people with AIDS. Common findings include LV systolic and diastolic dysfunction, pericardial effusion, infective endocarditis, cardiac malignancy, pulmonary hypertension, atherosclerosis, vasculitis, arrhythmia and lipodistrophy.[3] Our study found various abnormalities on echocardiography examination, which included systolic dysfunction (9.6\%), diastolic dysfunction (65.4\%), pericardial effusion $(26.9 \%)$ and pulmonary hypertension (67.3\%). In a cohort study of AIDS contribution to de novo presentations of heart disease, cardiomyopathy, pericardial effusion, and pulmonary hypertension were commonly found. [17] Moreover, chronic inflammation, frequent pericardial effusion, and probable myocardial edema were found to be associated in HIV infections. [18]

In the HIV-HEART study, the dominant sex was male, with a mean age of 44.2 years old and mean BMI of 24.1 $\mathrm{kg} / \mathrm{m}^{2}{ }^{19}$ In our study, the group was also predominately male (71.2\%), but with a younger age and lower BMI (33.3 years old and $16.5 \mathrm{~g} / \mathrm{m} 2$ respectively). These findings might be useful in minimizing the age-related and BMI-related effect on the pathological echocardiography findings, since both have been related to various abnormality findings in echocardiography. Older age is well known to increase the risk of diastolic dysfunction, while other cardiovascular risk factors such as hypertension, diabetes mellitus, and peripheral artery disease frequently comorbid in obese populations. $[2,6,20]$

The researchers found a larger number of diastolic dysfunction in our study then systolic dysfunction (31 samples with diastolic dysfunction, 3 samples with systolic dysfunction) This result was similar with a meta-analysis study that was done by Remick et al. in 2014 that found a higher rate of diastolic dysfunction among HIV/AIDS patients. ${ }^{10}$ Schuster et al. also found a high prevalence of LV diastolic dysfunction (64\%) in people with AIDS receiving an antiretroviral therapy. [22]

Cerrato et al. did a meta-analysis on 11 studies of HIV patients and found $31.8 \%$ had first grade diastolic dysfunction, $8.53 \%$ had second grade and $3.02 \%$ had third grade dysfunction. [23] Our study found a similar result in which a large percentage of patients with diastolic dysfunction had a first grade diastolic dysfunction (59.6\%), followed by second grade diastolic dysfunction (5.8\%).

As the increase of LVMI may reflect cardiac structural abnormality; it may also be related to the development or progression of diastolic dysfunction on HIV patients.[24] In the HIV-HEART study, they found that the LVMI values in HIV-infected patients were both significantly above the normal range in both sexes.[25] Our study found that the mean LVMI for both sexes were between normal ranges (male: 108.9, female 78.1). However, the researcher found that LVMI values were significantly higher in the sample group with CD4 counts of less than $200 / \mathrm{mm}^{3}$ than those with CD4 cell counts of more than $200 / \mathrm{mm}^{3}$ (113.08 vs. 87.9 respectively, $p=0.012$ ). These findings were consistent with a study done by Hsue et al. in 2010 that found higher LVMI values on HIV patients.[26] Ntusi et al. in their study using Cardiac Magnetic Resonance also found a similar result, which was proven unrelated to the BMI.[18]

Using logistic regression analysis, our study found that a CD4 count less than $200 / \mathrm{mm}^{3}$ stands as an independent predictor of diastolic dysfunction (OR: 9.35, CI 95\%, $p=$ 0.018) (see Table 3). The area under the curve (AUC) was significant for 0.756 , indicating CD4 as a good predictor of LV diastolic dysfunction with a cutoff point of 236.5 (Figure 1). A previous study of CD4 count as a predictor of cardiovascular morbidity found that a nadir CD4 count of less than $50 / \mathrm{mm}^{3}$ was an independent predictor of hypertension. $^{27}$ As hypertension and other conventional cardiovascular risks were excluded, the researchers did not evaluate their association in our study. However, the researchers found no significant difference in systolic and diastolic blood pressure between those with a CD4 count less than $200 / \mathrm{mm}^{3}$ and those with a CD4 count more than $200 / \mathrm{mm}^{3}$.

Our study also found that a CD4 count less than $200 / \mathrm{mm}^{3}$ was associated with a higher occurrence of pericardial effusion (10 vs. 4 findings of pericardial effusion in sample group with a CD4 count of less than $200 / \mathrm{mm}^{3}$ versus more than $200 / \mathrm{mm}^{3}$ respectively, $p=0.041$ ). In a logistic regression analysis, the researchers found that a CD4 count of less than $200 / \mathrm{mm}^{3}$ was a significant independent predictor of pericardial effusion (OR: 3.83 , CI $95 \%, p=$ 0.048). In a prospective multicenter cohort study of HIVinfected patient, Lind et al found that the incidence of pericardial effusion was low in the presence of CD4 counts of less than $200 / \mathrm{mm}^{3}$. [28]

Table 3. Logistic Regression Analysis on Predictors of Echocardiographic Abnormalities.

\begin{tabular}{lll}
\hline Variables & OR & $\boldsymbol{p}$ \\
\hline $\begin{array}{l}\text { LV Diastolic Dysfunction } \\
\text { CD4 count }<200 / \mathrm{mm}^{3}\end{array}$ & 9.35 & 0.018 \\
$\begin{array}{l}\text { Pericardial Effusion } \\
\text { CD4 count }<200 / \mathrm{mm}^{3}\end{array}$ & 3.83 & 0.048 \\
\hline
\end{tabular}

OR, Odds Ratio; LV, Left Ventricular; CD4, Cluster of Differentiation 4

Chronic inflammation process plays an important role in the development of pericardial effusion in people with AIDS, which also might be triggered by opportunistic infection, e.g. tuberculosis. In a study of 50 tuberculosis patients, it was found that $4 \%$ has diastolic dysfunction associated with the tuberculosis infection. [2] This study 
didn't found any specific infection that correlates significantly with the development of pericardial effusion nor diastolic dysfunction.

\section{Conclusion}

People with AIDS with low CD4 count had a higher risk of developing cardiac functional and structural abnormalities. Those with a CD4 count of less than $200 / \mathrm{mm}^{3}$ tend to have a higher LVMI, a higher risk of diastolic dysfunction and pericardial effusion.

\section{Conflict of Interest}

The authors declare that they have no competing interests.

\section{References}

[1] The Joint United Nations Programme on HIV/AIDS (UNAIDS). Global HIV Statistics. n.d. Available from: http://www.unaids.org/en/resources/fact-sheet.pdf

[2] Dasti MA, Hashmi SFA, Jaffri MSA, et al. Cardiac manifestations of pulmonary tuberculosis. Professional Med J. 2015;22(6):733-737.

[3] The DAD Study Group. Class of antiretroviral drugs and the risk of myocardial infarction. N Engl J Med 2007;356:17231735. https://doi.org/10.1056/NEJMoa062744

[4] Bloomfield GS, Alenezi F, Barasa FA, Lumsden R, Mayosi BM, Velazquez EJ. Human Immunodeficiency Virus and Heart Failure in Low- and Middle-Income Countries. JACC Heart Fail. 2015;3(8):579-590. https://doi.org/10.1016/j.jchf.2015.05.003

[5] Bozzette SA. HIV and Cardiovascular Disease. Clinical Infectious Disease. 2011;53:92-93. https://doi.org/10.1093/cid/cir275

[6] Hunt SA, Abraham WT, Chin MH, et al. ACC/AHA 2005 Guideline Update for the Diagnosis and Management of Chronic Heart Failure in the Adult: a report of the American College of Cardiology/American Heart Association Task Force on Practice Guidelines (Writing Committee to Update the 2001 Guidelines for the Evaluation and Management of Heart Failure): developed in collaboration with the American College of Chest Physicians and the International Society for Heart and Lung Transplantation: endorsed by the Heart Rhythm Society. Circulation. 2005;112:154-235. https://doi.org/10.1161/CIRCULATIONAHA.105.167586

[7] Frustaci A, Petrosillo N, Francone M, Verardo R, Ippolito G, Chimenti C. Biopsy-proven autoimmune myocarditis in HIVassociated dilated cardiomyopathy. BMC Infect Dis. 2014;14:3855-3860. https://doi.org/10.1186/s12879-014-0729-3

[8] Topol EJ, Califf RM, Isner JM, et al. (2002). Textbook of cardiovascular medicine, second edition. Lippincott Williams \& Wilkins. 2002;2:1991-97.

[9] Bernard A., Boumsell L., Hill C. (1984) Joint Report of the First International Workshop on Human Leucocyte Differentiation Antigens by the Investigators of the Participating Laboratories. In: Bernard A., Boumsell L.,
Dausset J., Milstein C., Schlossman S.F. (eds) Leucocyte Typing. Springer, Berlin, Heidelberg. 1984. https://doi.org/10.1007/978-3-642-68857-7 3

[10] Remick J, Georgiopoulou V, Marti C, et al. Heart failure in patients with human immunodeficiency virus infection: epidemiology, pathophysiology, treatment, and future research. Circulation. 2014;129(17):1781-1789. https://dx.doi.org/10.1161\%2FCIRCULATIONAHA.113.0045 74

[11] Bartel T, Muller S. How to relate diastolic left ventricular dysfunction to the results of stress echocardiography in aortic stenosis?. Cardiovasc Diagn Ther. 2013;3(4):190-192. https://dx.doi.org/10.3978\%2Fj.issn.2223-3652.2013.11.01

[12] Wu CK, Wang YC, Lee JK, et al. Connective tissue growth factor and cardiac diastolic dysfunction: human data from the Taiwan diastolic heart failure registry and molecular basis by cellular and animal models. Eur J Heart Fail. 2014;16(2):163172. https://doi.org/10.1002/ejhf.33

[13] Sipić T, Stambuk K, Trbović A, Kapov-Svilicić K, SzavitsNossan J, Bernat R. Echocardiographic assessment of revascularization completeness impact on diastolic dysfunction in ischemic heart disease. Coll Antropol. 2013;37(4):1299-1305.

[14] Paulus WJ, Tschöpe C. A novel paradigm for heart failure with preserved ejection fraction: comorbidities drive myocardial dysfunction and remodeling through coronary microvascular endothelial inflammation. J Am Coll Cardiol. 2013;62(4):263-271. https://doi.org/10.1016/j.jacc.2013.02.092

[15] Nagueh SF, Appleton CP, Gillebert TC, et al. Recommendations for the evaluation of left ventricular diastolic function by echocardiography. J Am Soc Echocardiogr. 2009;22(2):107-133. https://doi.org/10.1016/j.echo.2008.11.023

[16] Lang RM, Bierig M, Devereux RB, et al. Recommendations for chamber quantification: a report from the American Society of Echocardiography's Guidelines and Standards Committee and the Chamber Quantification Writing Group, developed in conjunction with the European Association of Echocardiography, a branch of the European Society of Cardiology. J Am Soc Echocardiogr. 2005;18(12):1440-1463. https://doi.org/10.1016/j.echo.2005.10.005

[17] Sliwa K, Carrington MJ, Becker A, Thienemann F, Ntsekhe M, Stewart S. Contribution of the human immunodeficiency virus/acquired immunodeficiency syndrome epidemic to de novo presentations of heart disease in the Heart of Soweto Study cohort. Eur Heart J. 2012;33(7):866-874. https://doi.org/10.1093/eurheartj/ehr398

[18] Ntusi N, O'Dwyer E, Dorrell L, et al. HIV-1-related cardiovascular disease is associated with chronic inflammation, frequent pericardial effusions, and probable myocardial edema. Circ Cardiovasc Imaging. 2016;9(3):4430 4438. https://doi.org/10.1161/CIRCIMAGING.115.004430

[19] Neumann T, Esser S, Potthoff A, et al. Prevalence and natural history of heart failure in outpatient HIV-infected subjects: rationale and design of the HIV-HEART study. Eur J Med Res. 2007;12(6):243-248.

[20] Wan SH, Vogel MW, Chen HH. Preclinical Diastolic Dysfunction. J Am Coll Cardiol, 2014;63(5): 407-416. https://dx.doi.org/10.1016\%2Fj.jacc.2013.10.063 
[21] Zile MR, Gaasch WH, Carroll JD, et al. Heart failure with a normal ejection fraction: is measurement of diastolic function necessary to make the diagnosis of diastolic heart failure?

Circulation. 2001;104(7):779-782.

https://doi.org/10.1161/hc3201.094226

[22] Schuster I, Thöni GJ, Edérhy S, et al. Subclinical cardiac abnormalities in human immunodeficiency virus-infected men receiving antiretroviral therapy. Am J Cardiol. 2008;101(8):1213-1217.

https://doi.org/10.1016/j.amjcard.2007.11.073

[23] Cerrato E, D'Ascenzo F, Biondi-Zoccai G, et al. Cardiac dysfunction in pauci symptomatic human immunodeficiency virus patients: a meta-analysis in the highly active antiretroviral therapy era. Eur Heart J. 2013;34(19):14321436. https://doi.org/10.1093/eurheartj/ehs471

[24] Lipshultz SE, Fisher SD, Lai WW, Miller TL. Cardiovascular risk factors, monitoring, and therapy for HIV-infected patients. AIDS. 2003;17(1):96-122. http://insights.ovid.com/pubmed?pmid=12870537
[25] Reinsch N, Kahlert P, Esser S, et al. Echocardiographic findings and abnormalities in HIV-infected patients: results from a large, prospective, multicenter HIV-heart study. Am J Cardiovasc Dis. 2011;1(2):176-184.

https://www.ncbi.nlm.nih.gov/pmc/articles/pmid/22254197/

[26] Hsue PY, Hunt PW, Ho JE, et al. Impact of HIV infection on diastolic function and left ventricular mass. Circ Heart Fail. 2010;3(1):132-139.

https://doi.org/10.1161/CIRCHEARTFAILURE.109.854943

[27] Manner IW, Trøseid M, Oektedalen O, Baekken M, Os I. Low nadir CD4 cell count predicts sustained hypertension in HIVinfected individuals. $\mathrm{J}$ Clin Hypertens (Greenwich). 2013;15(2):101-106. https://doi.org/10.1111/jch.12029

[28] Lind A, Reinsch N, Neuhaus K, et al. Pericardial effusion of HIV-infected patients? Results of a prospective multicenter cohort study in the era of antiretroviral therapy. Eur J Med Res. 2011; 16(11):480-483.

https://www.ncbi.nlm.nih.gov/pmc/articles/pmid/22027640/ 